\title{
Histopathology of acute human immunodeficiency virus exanthema
}

\author{
E Balslev, H K Thomsen, K Weismann
}

\begin{abstract}
Acute exanthema occurs in patients who are human immunodeficiency virus (HIV) positive before they become seropositive. The patients have influenza like symptoms and a macular skin rash on the upper trunk. Histopathological investigation of skin punch biopsy specimens from four patients with acute HIV exanthema showed a normal epidermis and a sparse dermal, mainly perivascular, lymphocytic/histiocytic infiltrate around vessels of the superficial plexus. Histopathological changes of the exanthema of acute HIV infection are non-specific and resemble those of other acute viral exanthema, but when both the histopathological features and the clinical picture are suggestive, the clinician should take into consideration the possibility of HIV infection.
\end{abstract}

AIDS is caused by a lymphocytopathic retrovirus known as human $\mathrm{T}$ lymphotrophic virus type III (HTLV III), ${ }^{1}$ AIDS associated retrovirus (ARV), ${ }^{2}$ or human immunodeficiency virus I (HIV-I). Acute HIV infection with a roseola like rash has recently been described. ${ }^{3-6}$ The illness is of sudden onset and lasts from one to two weeks. The patients complain of headache, myalgia, fever and sore throat. Skin rash develops on the upper trunk, neck, and face. Individual lesions are macular, often with a central deepened area. The size varies between 3-4 $\mathrm{mm}$ and $10-11 \mathrm{~mm}$. The skin rash is not itchy and fades within two weeks. Some of the patients have generalised lymphadenopathy. The patients are initially HIV antibody negative, but HIV antigen positive, showing seroconversion weeks later. ${ }^{356}$

Bispebjerg Hospital, Copenhagen, Denmark

The Department of

Pathology

E Balslev

H K Thomsen

The Department of

Dermatology

K Weismann

Correspondence to:

Dr Eva Balslev,

Department of Pathology,

University of Copenhagen

Hvidore Hospital, DK 2650

Denmark.

Accepted for publication

19 October 1989

\section{Methods}

Four patients with headache, myalgia, fever, sore throat and skin rashes were admitted to the dermatological department. Blood samples were taken for serological examination of HIV infection, syphilis, toxoplasmosis, cytomegalovirus infection, hepatitis B infection and Epstein-Barr virus infection. Skin punch biopsy specimens were taken from macular areas on the upper trunk. Paraffin wax embedded tissue was cut in $4 \mu \mathrm{m}$ thick sections and stained with haematoxylin and eosin and van-Gieson Hansen/alcian blue, and periodic acid Schiff.
Results

The epidermis was not affected: no parakeratosis, spongiosis, necrotic keratinocytes or hydropic degeneration of the basal cells were present. In one biopsy specimen a few lymphocytes were found focally in the lower third of epidermis. In the dermis a sparse, mainly perivascular, lymphocytic/histiocytic infiltrate was present around the vessels of the superficial plexus (figure). Plasma cells were not seen. The vessels did not seem to be changed and extravasation of erythrocytes was not noticed. The deeper part of the dermis was unaffected. In another biopsy specimen perifollicular infiltrates of lymphocytes and histiocytes were present. The hair follicles were dilatated with follicular plugs containing pityrosporum spores and demodectic mites.

The patients were initially HIV antibody negative. Seroconversion to HIV antibody positivity occurred three to nine weeks later. Other serological tests yielded negative results or indicated previous infection with cytomegalovirus or Epstein-Barr virus.

\section{Discussion}

The histopathological findings of these four cases with no or minimal epidermal changes and only a slight lymphocytic/histiocytic infiltrate around the superficial vascular plexus are changes found in many acute viral infections.

Clinically, the differential diagnosis includes pityriasis rosea, secondary syphilis and other viral or drug induced exanthemas.

Histologically the absence of epidermal changes except for a few lymphocytic cells in the lower part of the epithelium excludes pityriasis rosea. In some cases of secondary syphilis, especially in roseola, plasma cell infiltration is either absent or very sparse as are vascular changes. ${ }^{7}$ Such cases can not be differentiated from HIV exanthema by histological investigation. None of our patients had clinical or serological signs of syphilis. The histological changes in HIV exanthema are identical with those seen in other transient viral and drug induced exanthemas. The perifolliculitis observed in one biopsy specimen, most likely, was unrelated to HIV exanthema and must be regarded as an incidental finding.

Cutaneous vasculitis has been described in patients infected with HIV and circulating immune complexes and deposition of immune complexes have been shown in the dermal vessel walls. ${ }^{8}$ Acute HIV exanthema differs 


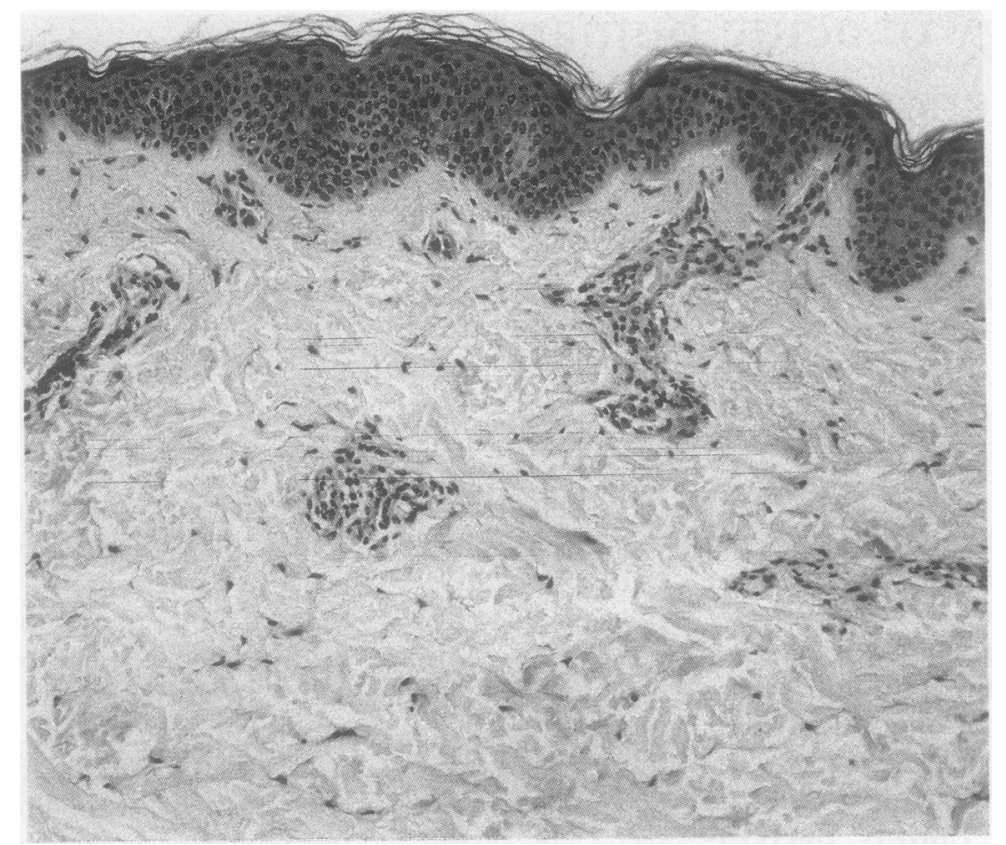

Skin punch biopsy specimen from the trunk showing sparse infiltration of mononuclear cells around the vessels of the superficial plexus.

from this condition as the histological examination did not show any signs of vasculitis.

It must be emphasised that the histopathological features of HIV exanthema are not diagnostic for HIV infection as the histology is the same as in many other virus infections. With the spread of the AIDS virus not only among homosexuals but also among heterosexuals, however, the clinician should take into consideration the possibility of HIV infection when both the histopathological features and the clinical picture are suggestive.

1 Gallo RC, Salahuddin SZ, Popovic M, et al. Frequent detection and isolation of cytopatic retroviruses (HTLV III) from patients with AIDS and at risk of AIDS. Science 1984;224:500-3.

2 Levy JA, Hoffman AD, Kramer SM, Landis JA Shimbukuro JM, Oshiro LS. Isolation of lymphoShimbukuro JM, Oshiro San Francisco patients with cytopathic retrovirus from $S$ an

3 Lindskov R, Orskov Lindhardt B, Weismann K, Ulrich K Wanzin GL. Acute HTLV III infection with roseola-like rash. Lancet 1986;i:447.

4 Ludlam CA, Tucker J, Steel CM, et al. T-lymphotrophic virus type III (HTLV III) infection in seronegative haemophiliacs after transfusion of factor VIII. Lancet 1985;i:233-6.

5 Cooper DA, Gold J, Maclean P, et al. Acute AIDS retrovirus infection. Definition of a clinical illness associated with seroconversion. Lancet $1985 ; \mathrm{i}: 537-40$.

6 Wanzin GL, Ørskov Lindhardt B, Weismann K, Ulrich K. Acute HTLV III infection associated with exanthema, diagnosed by seroconversion. Br J Dermatol 1985; diagnosed

7 Abell E, Marks R, Wilson JE. Secondary syphilis: A clinicopathological review. Br J Dermatol 1975;93:53-61. 8 Weismann K, Pedersen CS, Søndergaard J, Wanzin GL. Cutaneous vasculitis and purpura. In: Skin signs in AIDS Copenhagen: Munksgaard, 1988:100-2. 